\title{
Influência do agregado miúdo reciclado na resistência à compressão e porosidade do concreto
}

\author{
Paula Di Domenico'; Tainá Tamara Lima'; Rodrigo Martinez Castro'; Martha Nascimento Castrol \\ $\triangle$ pauladidomenico_@hotmail.com
}

1. Pontifícia Universidade Católica de Goiás, Goiânia - GO

Histórico do Artigo:
Recebido em: 20 de março de $2018 \quad$ Aceito em: 16 de maio de $2018 \quad$ Publicado em: 30 de junho de 2018

Resumo: A crescente geração de resíduos de construção e demolição vem trazendo preocupação e aumentando sua importância quanto à economia, ao meio ambiente e à saúde da população. Como forma de minimizar esses problemas, a utilização de agregados reciclados produzidos a partir desses resíduos garante que novos concretos e argamassas sejam produzidos reduzindo os impactos ao meio ambiente e financeiros, sem perda de performance das misturas. Vários estudos já foram realizados mostrando que é possível a utilização dos resíduos de construção e demolição como agregados para produção de concreto, argamassa, blocos de pavimentação, entre outros. 0 presente trabalho além de estudar variações dos teores de RCD, também analisa 0 impacto da variação da granulometria no resultado final do concreto com função estrutural. Com o ensaio de granulometria padronizou-se o agregado miúdo reciclado afim de que fosse produzido novo concreto tendo como análise seu comportamento quanto a resistência à compressão e permeabilidade. No programa experimental seguiu-se as normas para moldagem dos corpos-de-prova de concreto, rompimento dos corpos-de-prova e determinação da absorção de água do concreto no estado endurecido. De modo geral, os resultados de análise para a resistência apresentaram valores satisfatórios para concreto com substituição de agregado miúdo retido na peneira de $300 \mu \mathrm{m}$ e a absorção de água foi maior para todos os tratamentos que possuem agregado reciclado. Conclui-se que o uso do resíduo como forma de agregado miúdo para a confeç̧ão de novos concretos é possível e garantiu resultados de resistência satisfatórios inclusive à aplicação estrutural, ainda não normatizada.

Palavras-chave: resíduo de construção e demolição, impactos ambientais, resistência à compressão,

\section{Influence of fine recycled aggregate in concrete compressive strength and porosity} Abstract: The growing generation of construction and demolition waste has been causing concern and increasing
its importance as regards the economy, the environment and the health of the population. To minimize these
problems, the use of recycled aggregates produced from these residues ensures that new concretes and mortars
are produced to reducing environmental and financial impacts without loss of performance of the mixtures.
Several studies showed that it is possible to use construction and demolition waste as aggregates for the
production of concrete, mortar, paving blocks, among others. The present work besides studying variations of the
RCD contents, also analyzes the impact of the granulometry variation on the final result of the concrete with
structural function. With the grain-size distribution test, the fine recycled aggregate was standardized in order
to produce new concrete, analyzing its behavior regarding the compressive strength and permeability. In the
experimental program, the molding concrete specimens, breaking specimens and determining the water
absorption of concrete in the hardened state followed Brazilian technical standards. In general, the results of the
analysis for the resistance presented satisfactory values for concrete with substitution of kid aggregate retained
in the $300 \mu$ m sieve and the water absorption was higher for all the treatments that have recycled aggregate. The
conclusion is that the use of the residue as a fine aggregate for preparation of new concrete is possible and
guaranteed satisfactory results of resistance even to the structural application, which is not yet standardized.
Keywords: construction and demolition waste, environmental impacts, compressive strength, permeability. 


\section{Influencia del agregado reciclado en la resistencia a la compresión y porosidad del concreto}

Resumen: La creciente generación de residuos de construcción y demolición viene trayendo preocupación y aumentando su importancia en la economía, el medio ambiente y en la salud de la población. Para minimizar esos problemas, en la utilización de agregados reciclados producidos a prépartir de esos residuos garantiza que nuevos concretos y morteros se produzcan reduciendo los impactos al medio ambiente y financieros, sin pérdida de rendimiento de las mezclas. Varios estudios ya se han realizado indicando que es posible la utilización de los residuos de construcción y demolición como áridos para producción de concreto, mortero, bloques de pavimentación, entre otros. El presente trabajo además de estudiar variaciones de los contenidos de RCD, también analiza el impacto de la variación de la granulometría en el resultado final del concreto con función estructural. Con el ensayo de granulometría se estandarizó el agregado de restos reciclados a fin de que se produjera nuevo concreto teniendo como análisis su comportamiento como la resistencia a la compresión y la permeabilidad. En el programa experimental se siguieron las normas brasileñas para moldear los cuerpos de prueba de concreto, rompimiento de los cuerpos de prueba y determinación de la absorción del agua del concreto en el estado enrijecido. Los resultados de análisis para la resistencia presentaron valores satisfactorios para el concreto con sustitución de arenas por resto reciclado detenido en el tamiz de $300 \mu \mathrm{m}$ y la absorción de agua fue mayor para todos los tratamientos que poseen agregado reciclado. Se concluye que el uso del residuo como forma de agregado para la confección de nuevos concretos es posible y garantizó resultados de resistencia satisfactorios incluso a la aplicación estructural, aún no normalizada.

Palabras clave: residuos de construcción y demolición, impactos ambientales, resistencia a la compresión, permeabilidad.

\section{INTRODUÇÃO}

A geração de Resíduos de Construção e Demolição (RCD) cresceu com 0 desenvolvimento do mercado da engenharia civil nacional e, em companhia desses resíduos, cresceram também os estudos a respeito de como aproveitá-los na própria atividade geradora daqueles. A tecnologia da construção civil mostra-se empenhada em apresentar soluções para reduzir os impactos socioeconômicos e ambientais de suas atividades.

De acordo com Karpinski et al. (2009), a preocupação com o volume de RCD deve-se principalmente à sua disposição final na natureza. A opção mais comum para descarte desse material é feita diretamente em aterros, além das deposições irregulares que ocorrem em áreas de fácil acesso, como lotes baldios, encostas de rios e vias públicas. 0 descarte inadequado de resíduos de construção e demolição tem impacto direto sobre o meio ambiente, gerando problemas de drenagem, alteração no tráfego urbano e na paisagem local, assoreamento de rios, córregos e lagos, além da proliferação de doenças. 0 aproveitamento de RCD diminui o descarte inadequado, exploração de jazidas naturais e custos com administração e limpeza pública (MARTINS, 2012; CABRAL e MOREIRA, 2011). Como alternativa para solucionar tais problemas surge a reciclagem do resíduo de construção e demolição, utilizado como parte dos materiais de novas construções. 
Em estudos prévios, Tenório (2007), comprovou que, dependendo de sua composição, os resíduos podem ser incorporados em diferentes atividades da construção civil, e, na produção de concreto, encontram-se possibilidades promissoras. 0 concreto é o material mais produzido pela construção civil e o que mais causa impactos ao meio ambiente. Para sua confecção utiliza-se o cimento Portland, como elemento de ligação, de concretagem, e como aglomerante de elementos estruturais. Além daquele, há uma enorme demanda do consumo de agregados, usualmente areia e brita. Conforme Pullen et al. (2012), a produção de agregados naturais está relacionada a utilização de matérias-primas, emissão de gases poluentes, consumo de energia e de grande quantidade de água, o qual para Santoro e Kripka (2016) as etapas de extração, beneficiamento, armazenagem e transporte levam à alta produção de dióxido de carbono $\left(\mathrm{CO}_{2}\right)$, um dos gases que acentuam o efeito estufa.

Segundo John (2000), o crescimento dos grandes centros urbanos acelera o consumo de materiais naturais, fontes não renováveis, tornando imprescindível a busca por novas tecnologias de produção, como as dos agregados reciclados. A escassez dos agregados naturais próximos das áreas urbanas acarreta em maiores distâncias entre as novas construções e a fonte de material, aumentando o custo do transporte (HANSEN, 1992 citado por BAZUC0, 1999). 0 uso de agregados reciclados para a produção de concreto estrutural é uma alternativa para reduzir 0 valor de transporte de forma significativa (DOMINGUES, 2013). Este material tornase, então, uma alternativa para a produção de novos concretos e argamassas.

0 agregado reciclado é diferente dos agregados encontrados na natureza, pois já sofreu modificações quanto sua composição e características físico-químicas. Eles podem ser obtidos através de britagem e são constituídos por fragmentos de concretos, cerâmicas ou argamassas (ANGUL0 e FIGUEIRED0, 2011). Tenório (2007), afirma que os agregados reciclados possuem propriedades físicas diferentes dos agregados naturais. 0s agregados reciclados possuem maior porosidade devido ao alto teor de material cerâmico nos resíduos. A alta porosidade dos agregados atribui ao concreto perda na resistência à compressão e aumento da permeabilidade, podendo interferir no uso de concreto estrutural, havendo, então, a possibilidade de utilização em estruturas pouco expostas e com menor agressividade ambiental. Não existindo norma específica que padronize a utilização de agregados reciclados na produção de concreto, uma opção para minimizar tais efeitos é a diminuição da dimensão de suas partículas, já que possuem influência sobre a resistência, durabilidade, retração e permeabilidade do concreto. 
A fim de definir um método eficiente para a utilização de agregados provenientes do RCD devem-se estabelecer parâmetros granulométricos e quantitativos para produção de concreto. Portanto, o objetivo do trabalho foi analisar os valores de resistência à compressão e permeabilidade do concreto no estado endurecido.

\section{MATERIAL E MÉTODOS}

Para a elaboração do presente artigo, realizaram-se ensaios laboratoriais observando todas as normas técnicas brasileiras referentes ao tema do projeto, que foi fruto do trabalho de conclusão de curso dos autores. As coletas, análises e fases experimentais foram conduzidas no Laboratório de Concretos e Argamassas, Área 03, Bloco J, da Pontifícia Universidade Católica de Goiás, na cidade de Goiânia/G0, Lat. 1640'43.64"S, Long.49¹4'45.24"0 e a britagem dos agregados reciclados foi realizada no Laboratório da Empresa de Furnas GST. E, na Rodovia BR 153, s/n, Zona Rural, na cidade de Aparecida de Goiânia/G0. A elaboração do trabalho iniciou-se em agosto de 2016 e foi concluído em agosto de 2017, totalizando um ano de pesquisas e ensaios.

0 programa experimental iniciou-se com a produção de agregados reciclados a partir de resíduos de construção e demolição. A coleta foi feita a partir de materiais oriundos da demolição de elementos estruturais, retirados de uma reforça da unidade de Ciências da Computação da Pontifícia Universidade Católica de Goiás, sendo o material classificado pelos tipos e tamanhos encontrados dos resíduos e, após esta seleção, transferidos para o Laboratório de Materiais de Construção do Complexo de Furnas, no qual foram triturados a partir do tamanho de 5,66mm (dimensão da abertura do britador) utilizando-se de um britador de resíduos, marca Marobrás, modelo CH2010 e de um conjunto de esteira e peneira vibratória inclinada, marca Simplex, modelo SXR2510/4D (Figura 1).

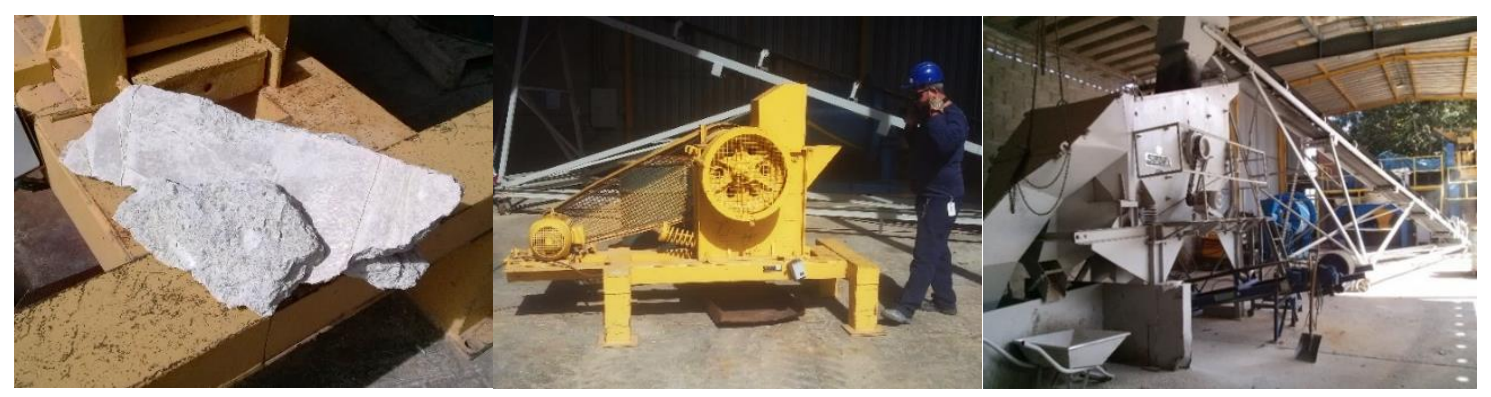

Figura 1. Resíduo de demolição inicial, britador e conjunto de esteiras Fonte: Autores, 2017 
Influência do agregado miúdo reciclado na resistência à compressão e porosidade do concreto

Em seguida, o material foi espalhado na esteira mecânica, que por sua vez, lançou-o na peneira vibratória e o subdividiu em agregado miúdo (menor que 4,75mm), brita 0 (entre 4,75mm e 9,5mm) e brita 1 (entre 9,5mm e 19mm), calibrações essas, possíveis e limitadas pelo próprio equipamento.

Posteriormente, foi feita a classificação granulométrica dos resíduos obtidos, de acordo com ABNT NBR7211:2009 - Agregado para concreto - especificação.

Após terem sido classificados e divididos em agregados miúdos (menores que 4,75mm) e graúdos (maiores que 4,75mm), os agregados miúdos foram divididos em quatro séries granulométricas para a confecção do concreto, conforme ABNT NM248:2003 - Agregados Determinação da composição granulométrica:

a) partículas retidas entre as peneiras de $n^{0} 4$ e $n^{0} 8$ (4,75mm e 2,36mm);

b) partículas retidas entre as peneiras de $n^{0} 8$ e $n^{0} 16$ (2,36mm e 1,18mm);

c) partículas retidas entre as peneiras $n^{\circ} 16$ e $\mathrm{n}^{\circ} 30(1,18 \mathrm{~mm}$ e $600 \mu \mathrm{m})$;

d) partículas retidas entre as peneiras $\mathrm{n}^{0} 30$ e $\mathrm{n}^{0} 50(600 \mu \mathrm{m}$ e $300 \mu \mathrm{m})$, para posterior aplicação.

0 material coletado após a britagem no equipamento foi dividido em frações, de onde foram anotadas suas dimensões de partículas e respectivas quantidades obtidas em quilogramas (Tabela 1).

Após a separação, foi realizada a produção de concreto objetivando resistência 25MPa, com vistas ao valor mínimo exigido para concreto estrutural, de acordo com a ABNT NBR6118:2014 - Projeto de estruturas de concreto - Procedimento.

Baseando-se na literatura de Ambrozzewicz (2012), definiu-se que o traço para confeç̧ão do concreto seria 1:1,025:2,475:0,510 com slump $80 \pm 20 \mathrm{~mm}$ e teor de argamassa de 0,45. 0 cimento utilizado foi o da marca Cauê - Uso Geral, de classificação CPII E32.

Na produção do concreto, foram utilizados agregados reciclados na proporção de 0\%, 15\% e 25\%, em substituição ao agregado miúdo do traço estudado, utilizando-se das diferentes faixas granulométricas obtidas pelo processo de britagem (Quadro 1).

Foram moldados 12 corpos-de-prova para cada tratamento, utilizando-se 3 corpos-deprova para cada intervalo de rompimento conforme norma, ou seja, aos 3, 7, 14 e 28 dias após a moldagem. 
Quadro 1. Denominação dos tratamentos conforme sua composição

Fonte: Autores, 2017

\begin{tabular}{|c|c|c|}
\hline Tratamento & Porcentagem de RCD & Faixa Granulométrica \\
\hline Testemunha & $0 \%$ & - \\
\hline Composto $15 \%$ & $15 \%$ & $1,18 \mathrm{~mm}$ a $300 \mu \mathrm{m}$ \\
\hline Composto $25 \%$ & $25 \%$ & $1,18 \mathrm{~mm}$ a $300 \mu \mathrm{m}$ \\
\hline P16 15\% & $15 \%$ & $2,36 \mathrm{~mm}$ a $1,18 \mathrm{~mm}$ \\
\hline P16 25\% & $25 \%$ & $2,36 \mathrm{~mm}$ a $1,18 \mathrm{~mm}$ \\
\hline P50 15\% & $15 \%$ & $600 \mu \mathrm{m}$ a $300 \mu \mathrm{m}$ \\
\hline P50 25\% & $25 \%$ & $600 \mu \mathrm{m}$ a $300 \mu \mathrm{m}$ \\
\hline
\end{tabular}

Para correlacionar a permeabilidade com a resistência do concreto, fora realizado 0 ensaio descrito pela ABNT NBR9778-2:2009 - Argamassa e concreto endurecidos Determinação da absorção de água, índice de vazios e massa específica. Após um dia de moldagem, dois corpos-de-prova de cada tratamento foram separados e tiveram suas massas (massa seca) aferidas. Em seguida, foram deixados em imersão em água à temperatura controlada por 24 horas, e, quando retirados, mediu-se novamente suas massas (massa úmida). Os valores estão apresentados no item correspondente e originaram o cálculo do índice de absorção de água médio percentual (Tabela 2).

Para definir a resistência do concreto, os corpos-de-prova foram ensaiados à compressão, conforme a ABNT NBR5738:2016 Concreto - Procedimento para moldagem e cura de corpos-de-prova. Foram efetuados os ensaios de compressão axial, em prensa eletro hidráulica fabricada pela EMIC (Instron Brasil Equipamentos Científicos LTDA), modelo PC200C, que atende a todos os parâmetros estabelecidos pela ABNT NBR NM IS07500-1:2016 Materiais metálicos - Calibração e verificação de máquinas de ensaio estático uniaxial. 0 ensaio foi realizado seguindo os parâmetros da ABNT NBR5739:2007 - Concreto - Ensaio de compressão de corpos-de-prova cilíndricos, aplicando-se uma força axial constante de $(0,45 \pm$ $0,15) \mathrm{MPa} / \mathrm{s}$ no centro dos corpos-de-prova.

Após a realização do ensaio de resistência à compressão axial do concreto, foi feita a comparação entre os valores obtidos com os corpos-de-prova produzidos com os diferentes teores de RCD e diferentes granulometrias. Também foi analisada a relação entre os valores de absorção de água obtidos com diferentes tratamentos. Para amparo estatístico das comparações, foram demonstrados ainda os índices estatísticos simples dos valores apresentados, sendo eles absorção média (sendo o valor médio dos três corpos-de-prova para cada idade de tratamento), desvio padrão (que tem como função apresentar o quanto aquele 
Influência do agregado miúdo reciclado na resistência à compressão e porosidade do concreto

valor está discrepante da média) e o coeficiente de variação (que demonstra a dispersão dos dados, ou seja, qual a precisão dos mesmos).

\section{RESULTADOS E DISCUSSÃ0}

0s valores em massa resultantes das pesagens do RCD britado e peneirado totalizaram $68,06 \mathrm{Kg}$ de material e as quantidades obtidas são descritas abaixo (Tabela 1), de acordo com as malhas das peneiras utilizadas.

Tabela 1. Faixas granulométricas do material britado (brit) em Furnas/G0

\begin{tabular}{l|l|l|l|l|l|l|l|l}
\hline Peneira Retida & 4 & 8 & 16 & 30 & 50 & 100 & 200 & Total \\
Origem & Brit. & Brit. & Brit. & Brit. & Brit. & Brit. & Brit. & (Kg) \\
Massa (Kg) & 0,27 & 15,7 & 12,45 & 9,37 & 25,32 & 4,01 & 0,89 & 68,06 \\
\hline
\end{tabular}

\section{Permeabilidade do concreto}

Os resultados de absorção de água correspondem ao apresentado na sequência (Tabela 2). 0 menor coeficiente de variação foi o do tratamento P50 com $25 \%$ de substituição do agregado miúdo reciclado, e o maior coeficiente de variação foi 0 do tratamento composto pela mistura com 15\% de substituição do agregado miúdo reciclado. 0 tratamento composto de 25\%, de maior valor médio, possui 94,5\% maior absorção de água quando comparado ao tratamento Testemunha. Já o tratamento P16 15\%, que é o de menor valor médio, possui 31,9\% menor absorção de água frente à mesma comparação.

Tabela 2. Absorção de água por tratamento.

\begin{tabular}{|c|c|c|c|c|c|c|c|}
\hline Tratamento & Test. & $\begin{array}{l}\text { Comp } \\
15 \%\end{array}$ & $\begin{array}{l}\text { Comp } \\
25 \%\end{array}$ & $\begin{array}{l}\text { P16 } \\
15 \%\end{array}$ & $\begin{array}{l}\text { P16 } \\
25 \%\end{array}$ & $\begin{array}{l}\mathrm{P} 50 \\
15 \%\end{array}$ & $\begin{array}{l}\mathrm{P} 50 \\
25 \%\end{array}$ \\
\hline $\begin{array}{l}\text { Índice de Médio Absorção } \\
(\%)\end{array}$ & 0,91 & 1,10 & 1,77 & 0,69 & 1,46 & 1,27 & 1,32 \\
\hline Des. Padrão & 0,19 & 0,98 & 1,27 & 0,09 & 0,07 & 0,05 & 0,02 \\
\hline Coef. Variação (\%) & 0,21 & 0,89 & 0,72 & 0,14 & 0,05 & 0,04 & 0,02 \\
\hline
\end{tabular}

Fonte: Autores, 2017 
Os tratamentos compostos de $15 \%$ e $25 \%$ de substituição de agregado apresentaram coeficiente de variação alto (maior do que 30\%), indicando possivelmente uma alta dispersão dos dados, e, também alto desvio padrão. Isso explica-se dado ao fato que os dois valores do ensaio de absorção estiveram muito distantes da própria média, e que o experimento não obteve quantidade suficiente de amostras para que fosse possível assertividade das conclusões.

Em sentido contrário, os tratamentos P16 e P50, possuem coeficiente de variação baixo (menor que 15\%) para ambos índices de absorção, demonstrando que os dados de entrada desses tratamentos foram mais homogêneos e implicaram em uma média homogênea. Estatisticamente, tanto o P16 quanto o P50 obtiveram boas amostras, e observou-se que os tratamentos P50 15\%, P50 25\% e P16 25\% possuem médias de absorção de água maiores quando comparados com o tratamento Testemunha, e, que o P16 15\% foi o único que atingiu uma média de absorção menor que o tratamento Testemunha.

Considerando-se uma análise da média da absorção de água, e unificando os valores dos índices de P16 e de P50, obteve-se, respectivamente, 1,08 e 1,30. Se comparados ao valor médio do tratamento Testemunha (0,91\%), tem-se que os tratamentos P16 e P50 apresentaram absorção de água maior em 18,7\% e 42,9\% respectivamente. Portanto, pode-se afirmar que os tratamentos com agregado reciclado absorveram mais água (Gráfico l).

Gráfico 1. Média de absorção de água por tratamento

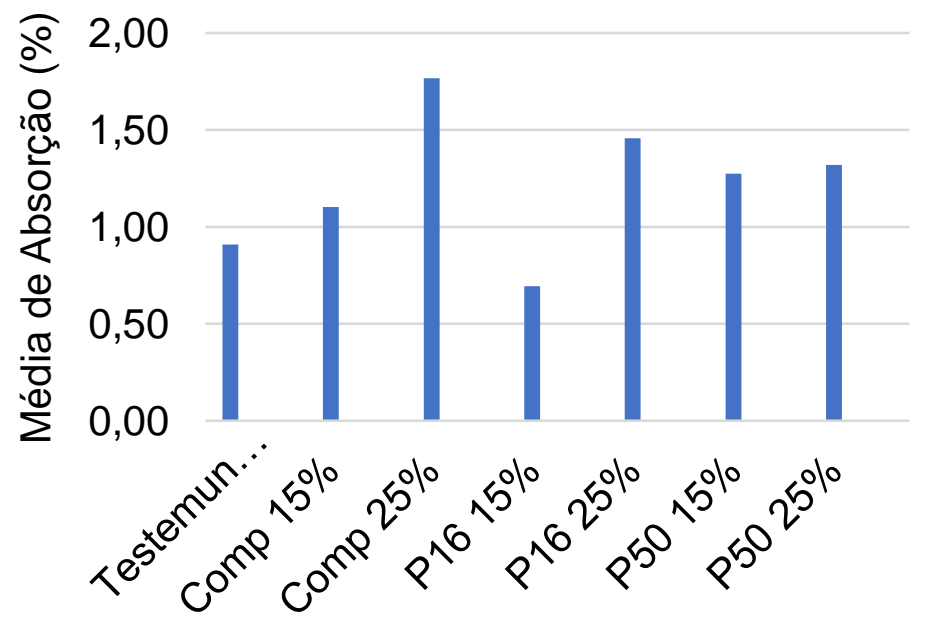

Fonte: Autores, 2017

Nota-se (Gráfico 1) que o tratamento composto de mistura com 25\% de substituição do agregado miúdo reciclado obteve o maior índice de absorção médio, ou seja, absorveu maior 
quantidade de água, sendo 157\% maior que o tratamento Testemunha. Através do gráfico, observa-se ainda que os tratamentos com 25\% de substituição do agregado natural pelo reciclado foram os que obtiveram maiores absorções médias, ou seja, pode-se afirmar que quanto maior a porcentagem de substituição do agregado, maior será o valor médio da absorção de água. Além disso, pode-se afirmar também que os tratamentos com agregados de menores dimensões (P50) absorveram mais água se comparados aos tratamentos P16 e ao Testemunha.

Uma peça estrutural com maior potencial de absorção de água possui limitação de uso quando a estrutura for aparente (TENÓRIO, 2007). Porém, a ANBR NBR6118:2014, estipula valores mínimos de cobrimento para peças expostas às quatro condições de agressividades ambientais, podendo o uso do concreto com agregado reciclado ser considerado aceito em casos onde a agressividade for menor.

A utilização de concreto com maior absorção de água, ou seja, com maior porosidade também é interessante na utilização em pavimentos permeáveis, já que tais estruturas necessitam de maior drenagem, portanto, a substituição do agregado natural pelo agregado reciclado pode ser utilizada na produção de concretos para pavimentação (TAVARES e KAZMIERCZAK, 2016). Além da porosidade interferir na absorção de água, também sabemos que concretos mais porosos implicam em estruturas mais leves, sem que haja necessariamente perda de resistência em função da alteração da densidade, podendo o uso ser interessante na construção de lajes mistas, por exemplo, onde os vãos podem ser maiores, já que a estrutura metálica receberá cargas menores, o que flexibiliza a utilização desse tipo de sistema construtivo (G0MES, 2001).

A maioria das composições apresentaram maior absorção se comparadas ao concreto comum (Testemunha), exceto pelo concreto preparado com 15\% de agregado reciclado retido na peneira $n^{0} 16$ (Gráfico 1), que pode ter deixado a mistura mais homogênea e com menor número de vazios. De modo geral, concretos feitos com substituição parcial de agregado miúdo natural por agregado miúdo reciclado tendem a apresentar maior absorção de água (MOREL, 1993 citado por BAZUC0, 1999).

A capacidade de absorção de água determina qual é o potencial que um concreto possui em adquirir determinadas manifestações patológicas, como eflorescência, ataque por sulfatos, reação álcali-agregado, carbonatação e corrosão das armaduras. A água possui a capacidade de deterioração, sendo por si só ou em combinação com outros agentes agressivos, já que se torna veículo de transporte para que agentes deletérios consigam chegar ao interior 
do concreto (FIGUEIRED0 et al, 2016). Logo, quanto maior for o índice de absorção de água de um concreto, maior será a exposição do mesmo à entrada de materiais indesejáveis.

De acordo com Hoppen et al. (2006), concretos que apresentem absorção de água menor que $10 \%$ apresentam boa qualidade para serem utilizados no lado interno da obra, onde o contato com a água não seja constante. Além disso, para concretos usados na fabricação de postes e cruzetas, a absorção de água deve ser inferior a 5,5\% (ABNT NBR8451-1:2012 - Postes de concreto armado e protendido para redes de distribuição e de transmissão de energia elétrica - Requisitos). Sendo assim, todos os tratamentos utilizados no experimentam podem ser classificados como concretos de boa qualidade para produção de postes de concreto, no quesito absorção de água.

Concretos produzidos com agregados reciclados tendem a ser mais porosos (BAZUCO, 1999). Foi observado durante o ensaio de permeabilidade que concretos produzidos com agregados miúdos oriundo de RCD apresentaram o índice de absorção de água maior do que o concreto produzido com agregado natural. Notou-se também que o índice de absorção de água aumentou quando o teor de substituição parcial por agregado reciclado foi maior.

\section{Resistência à compressão}

Para todos os tratamentos em todas as idades, foram tabelados os valores de resistência à compressão (Tabela 3). Considerando os valores de desvio padrão, o maior deles ocorreu no tratamento P16 com 15\% de substituição de agregado miúdo reciclado aos 28 dias de idade, e o menor desvio padrão se deu no tratamento P16 15\% aos 3 dias de idade. 0 maior coeficiente de variação foi do tratamento P16 15\% aos 28 dias de idade. Já o menor coeficiente de variação também foi do tratamento P16 15\% aos 3 dias de idade.

Tabela 3. Valores de resistência à compressão por tratamento

\begin{tabular}{c|ccc|c|c|c}
\hline Tratamento & & & & $\begin{array}{c}\text { Média } \\
\mathbf{( \% )}\end{array}$ & $\begin{array}{c}\text { Desv. } \\
\text { Padrão }\end{array}$ & $\begin{array}{c}\text { Coef. } \\
\text { Variação } \\
\mathbf{( \% )}\end{array}$ \\
Testemunha & 12,1 & $\begin{array}{c}3 \text { dias } \\
16,2\end{array}$ & 17,2 & 15,2 & 2,7 & 17,8 \\
Comp 15\% & 14,7 & 17,3 & 17,5 & $\underline{16,5}$ & 1,6 & 9,5 \\
Comp 25\% & 12,0 & 16,1 & 18,6 & $\underline{15,6}$ & 3,3 & 21,4 \\
P16 15\% & 15,2 & 15,5 & 15,9 & $\underline{15,5}$ & 0,3 & 2,1 \\
P16 25\% & 12,3 & 12,6 & 13,7 & 12,9 & 0,8 & 5,9 \\
P50 15\% & 15,7 & 16,8 & 17,7 & $\underline{16,7}$ & 1,0 & 6,1 \\
P50 25\% & 12,3 & 14,3 & 14,8 & 13,8 & 1,3 & 9,7
\end{tabular}




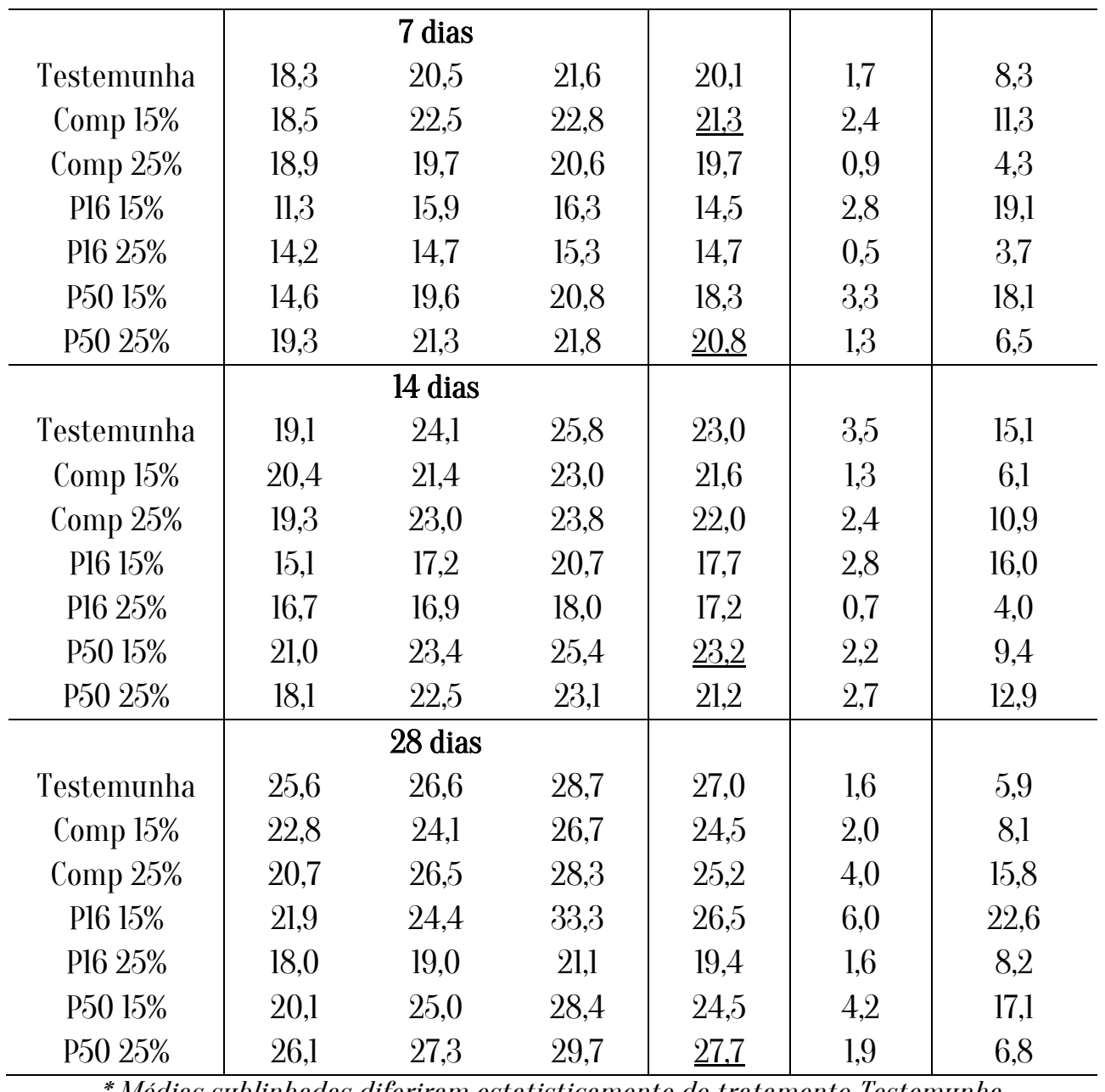

Fonte: Autores, 2017

Médias sublinhadas diferiram estatisticamente do tratamento Testemunha.

Inicialmente (Tabela 3), o processo de cura no tratamento P16 15\% ocorreu de forma efetiva e uniforme, inclusive melhor que o tratamento Testemunha. Porém, ao longo do tempo da reação de hidratação, nota-se a queda da eficácia da reação, explicada neste caso pela presença de partículas maiores dos reciclados utilizados. A ação da cura pode ter sido alterada nesse tratamento devido um aumento excessivo de temperatura inicial fazendo com que o processo de hidratação do cimento fosse acelerado e depois, ao decorrer das próximas idades, ocorresse uma queda nesse processo, aumentando o desvio padrão.

A maioria dos coeficientes de variação (Tabela 3) apresentaram, em todas as idades, baixa dispersão de dados, o que significa que, mesmo com possíveis e eventuais falhas previstas de prensagem em rompimento, houve uma homogeneidade dos valores encontrados para o resultado de resistência, ou seja, os resultados permaneceram dentro do estatisticamente esperado. Porém, o tratamento P16 e o Composto 25\% apresentaram coeficientes de variação maiores, denotando uma maior variação dos valores entre os corpos- 
de-prova na mesma idade, apresentados pela possível reação dos finos da mistura, menos previsíveis que as demais granulometrias.

Observando os valores médios de resistência à compressão (Tabela 3) de forma separada para cada idade de rompimento, aos 3 dias, todos os tratamentos com 15\% de substituição de agregado obtiveram as maiores resistências. Aos 7 dias, a maioria dos resultados foram menores que o tratamento Testemunha, com exceção do Composto 15\% e do P50 25\%, apontando que todo tratamento com agregado reciclado reagiu adequadamente em mistura durante os primeiros 3 dias, e que depois, sua velocidade de reação de hidratação diminuiu aos 7 dias. 0 agregado reciclado apresentou resistência mais alta nas primeiras idades, quando comparada ao agregado natural, indicando uma rápida reação, mas que pelos demais resultados não permanece.

Ainda em análise por períodos, já aos 14 e aos 28 dias, somente o P50 15\% e P50 25\%, respectivamente, tiveram resistência maior quando comparados ao Testemunha. No geral, observa-se que os tratamentos com agregado de maiores dimensões (P16) tiveram resistência menor quando comparados com os tratamentos de agregado com menor tamanho (P50), que por sua vez resultaram em maiores resistências aferidas (Tabela 3).

Analisando os dados mostrados (Tabela 3), em que os concretos produzidos com agregado reciclado apresentaram valores de resistência média mais altas nas primeiras idades, o processo de cura do concreto contendo agregado reciclado mostrou-se mais rápido nos primeiros dias e depois perdeu velocidade, quando comparado ao concreto com agregado natural. De acordo com Machado (1998) citado por Bazuco (1999), isso pode ocorrer devido a absorção de água livre da mistura ou até mesmo absorção da nata de cimento pelo agregado reciclado seco, aumentando a resistência inicial.

Com os resultados dos 14 e 28 dias (Tabela 3), afirma-se, então, que concretos produzidos com agregados mais finos apresentam resistências mais altas. Agregados com menores dimensões preenchem melhor os espaços vazios do concreto, além de diminuir a segregação, ajudar no efeito de empacotamento e contribuir para o fechamento dos vazios, tornando a matriz mais densa, melhorando a zona de transição e, consequentemente, aumentando a resistência do concreto (LEITE, 2001). Em qualquer época de rompimento, o tratamento P50, seja com 15\% ou 25\% de substituição, apresentou alguma das resistências maior que o Testemunha, indicando que a padronização torne possível a aplicação do agregado reciclado sem perda de resistência na produção de novos concretos. 
Para melhor compreensão dos valores de resultados tabelados (Tabela 3), foram elaborados os gráficos com os valores de resistência à compressão para cada tipo de tratamento aplicado, nas idades de 3, 7, 14 e 28 dias, objetivando uma análise comparativa visual dos mesmos, sendo demonstrados os resultados em formas de barras e de curvas (Gráficos 2, 3 e 4).

Gráfico 2. Valores de resistência e resistência média à compressão para o concreto composto

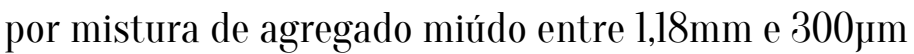

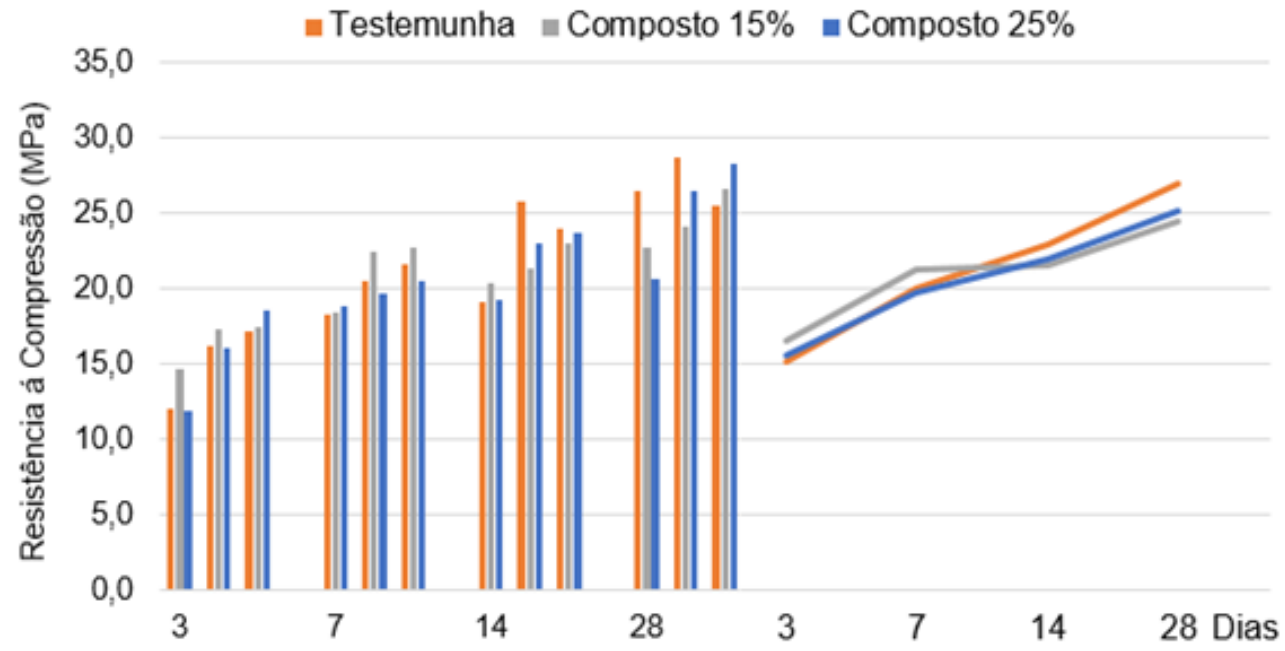

Fonte: Autores, 2017

De acordo com a primeira análise comparativa no gráfico de barras (Gráfico 2), aos 3 e 7 dias de idade, o tratamento Composto 15\% obteve resultados de compressão maiores que os do Testemunha, enquanto o Composto $25 \%$ demonstrou valores aproximados a ele, inferindo que um aumento do teor de substituição diminuiu o valor da resistência inicial. A partir dos 14 dias, o tratamento Testemunha apresentou valores maiores que os demais tratamentos. Aos 28 dias, o tratamento Composto 15\% mostrou resistência 7,5\% menor que o Testemunha, e 0 Composto 25\% apresentou resistência 1,4\% menor que o Testemunha. De modo geral, a resistência dos Compostos $15 \%$ e $25 \%$ apresentaram resistências consideráveis e estatisticamente próximas do Testemunha.

No gráfico em que são representadas as curvas das resistências médias à compressão (Gráfico 2), os valores de resistência à compressão dos tratamentos P50 15\% e P50 25\% mantiveram-se próximos aos valores do Testemunha durante todo o monitoramento. Nota-se pelo gráfico que o concreto fabricado com agregados reciclados, composto por mistura de agregado miúdo retido nas peneiras $n^{0} 16$ e $n^{0} 50$, apresentam resistência aos 3 dias superior ao 
Testemunha. Durante os primeiros 7 dias, a resistência do P50 15\% permanece superior aos demais tratamentos, e, a partir dos 14 dias a resistência do Testemunha torna-se superior aos tratamentos P50, e mantém essa superioridade até o final do ensaio. Mesmo com valores próximos, a resistência final do tratamento Testemunha foi maior que às dos tratamentos analisados.

Conforme exposto (Gráfico 2), de acordo com Leite (2001), concretos com agregado reciclado tendem a apresentar uma rápida evolução de hidratação devido à alta taxa de absorção do agregado, uma vez que há uma diminuição na quantidade de água na mistura. Essa diminuição de água faz com que os cristais de etringita e de hidróxido de cálcio cresçam menos e deixem a pasta mais densa, acarretando em um rápido ganho de resistência nos primeiros dias.

Gráfico 3. Valores de resistência e resistência média à compressão para o concreto composto por agregado miúdo de 1,18mm.

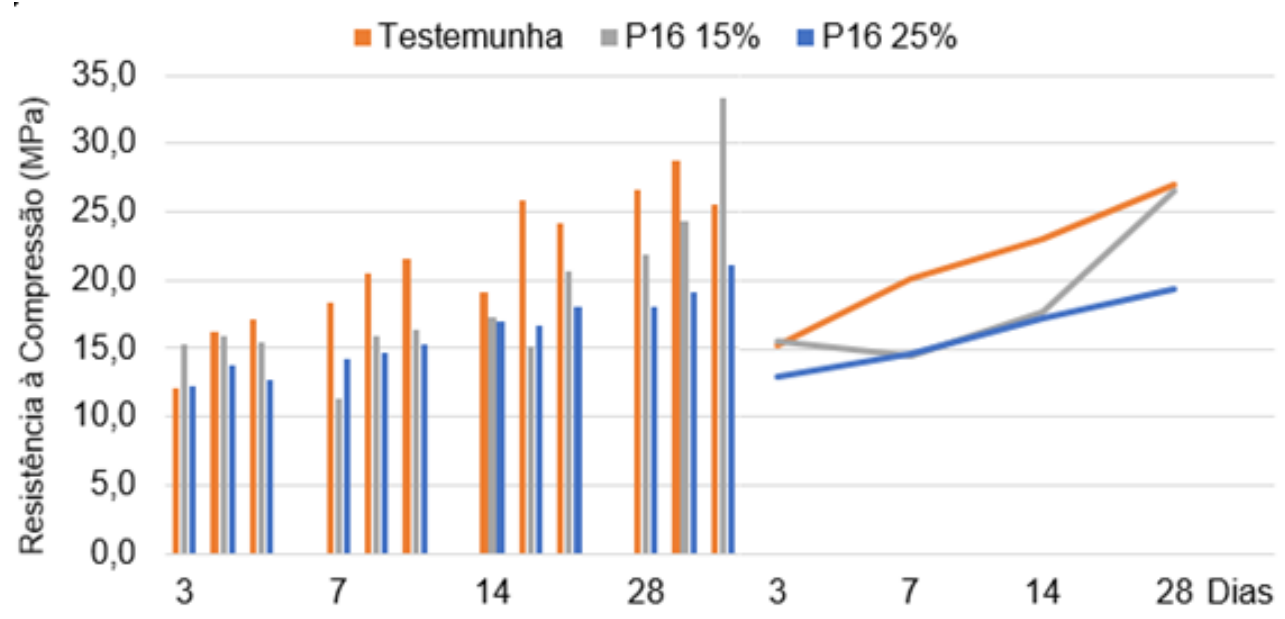

Fonte: Autores, 2017

Durante todas as idades comparativamente analisadas em barras para os tratamentos P16 (Gráfico 3), nota-se que o tratamento Testemunha manteve resistência maior que os tratamentos propostos de 15\% e 25\%. Aos 28 dias de idade, o P16 15\% apresentou resistência 16\% maior que o Testemunha. Já o P16 25\% obteve resistência menor que o Testemunha em $36 \%$. A resistência final do P16 15\% foi 110\% maior que o Testemunha e 160\% maior que o P16 25\%. Notoriamente, a resistência do Testemunha se sobressai em relação aos demais tratamentos, exceto o P16 15\% aos 28 dias que superou os outros valores. Esse resultado foi influenciado pela dimensão do agregado, pois quando comparado com o tratamento P50 
(granulometria do agregado reciclado menor), também mostrou resultados maiores (Gráfico 4 confirmado pela Tabela 3).

Analisando o gráfico de curvas (Gráfico 3), durante a idade inicial (3 dias), P16 15\% apresentou a maior resistência média à compressão e P16 25\% o menor valor relativo. Aos 7 e 14 dias o tratamento Testemunha mostrou-se superior, mantendo essa expressividade até o final do ensaio. A resistência média final do tratamento Testemunha foi a maior, porém com proximidade relativa ao tratamento P16 15\%, apresentando bom desempenho do mesmo quanto a capacidade de manter a resistência à compressão. 0 tratamento P16 25\% manteve os menores resultados em todas as idades, enquanto P16 15\% teve um elevado aumento de valores a partir dos 14 dias, ficando com resistência média final próxima do Testemunha, denotando que uma maior adição de agregados reciclados desta faixa granulométrica pode ser deletéria às características desejadas do concreto, e que adições até a faixa de 15\% em substituição com tamanho entre 2,36mm e 1,18mm pode ser totalmente segura à resistência final. A substituição de 15\% deste agregado torna-se favorável para produção de concretos com resistências superiores a 25MPa (valor mínimo para concreto estrutural estipulado pela ABNT NBR6118:2014).

Discutindo ainda, (Gráfico 3, em curvas), a queda de resistência apresentada pelo tratamento P16 15\% aos 7 dias pode ser relacionada a problemas de moldagem e/ou cura das amostras de corpos-de-prova para essa idade, o que justifica o porquê de a resistência aos 3 dias de idade ter sido maior que aos 7 dias e, aos 14 e 28 dias a resistência ter continuado com o aumento.

Gráfico 4. Valores de resistência e resistência média à compressão para 0 concreto composto por agregado miúdo de $300 \mu \mathrm{m}$.

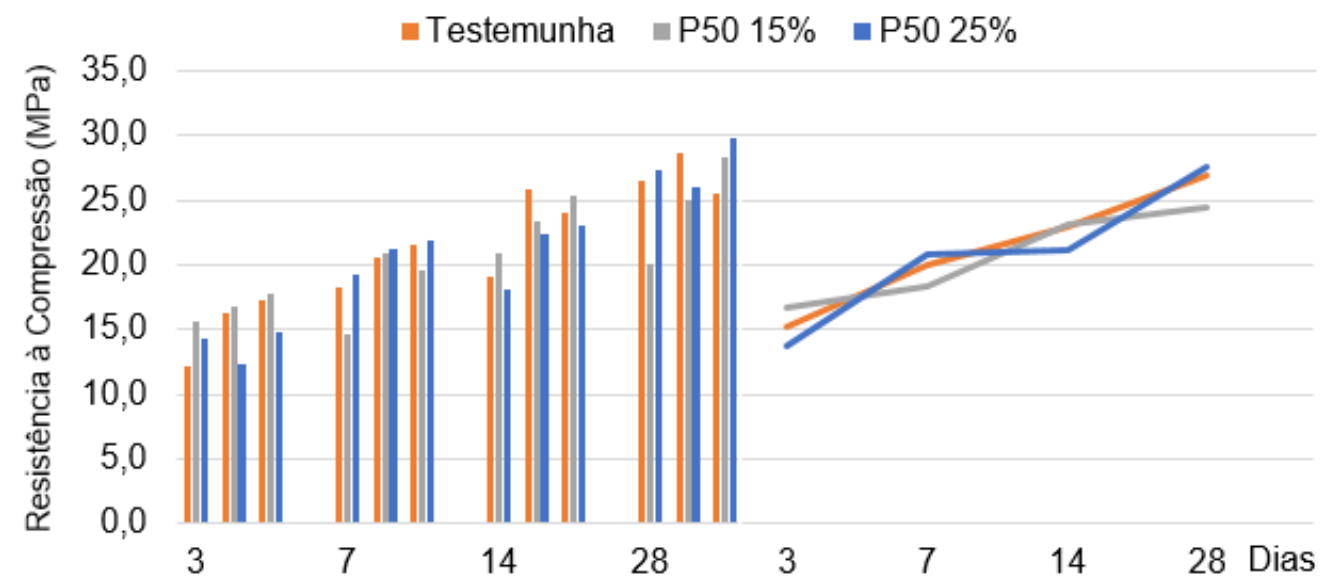

Fonte: Autores, 2017 
As análises do tratamento P50 (Gráfico 4, em barras) denotam que a substituição em 15\%, aos 28 dias de idade, apresentou redução de 1,1\% na resistência comparada ao Testemunha, e o tratamento P50 25\% apresentou 3,5\% mais resistência na mesma comparação. A resistência inicial (aos 3 dias) do Testemunha foi menor quando comparado ao P50 15\%, e a resistência final (aos 28 dias) do Testemunha foi maior se comparado com 0 mesmo tratamento, indicando que o agregado com maior teor de finos preenche melhor os poros do concreto e, consequentemente, apresenta densidade que implicou em ganho de resistência.

Em geral, o P50 obteve resultados próximos ao Testemunha (Gráfico 4 confirmado pela Tabela 3), tendo em alguns momentos o ultrapassado, ou seja, os resultados de resistência à compressão com a substituição parcial do agregado miúdo natural pelo reciclado retido na peneira $\mathrm{n}^{050}$ atendem aos valores mínimos exigidos pela ABNT NBR6118:2014 - Projeto de estruturas de concreto, de 25MPa, ora com assertividade, ora com folga de resistência.

0 tratamento P50 15\% apresenta o maior valor de resistência média e o P50 25\% 0 menor valor, utilizando a comparação ao Testemunha em suas respectivas idades iniciais de rompimento. Aos 7 dias ocorre uma inversão, o tratamento com 25\% apresenta 0 maior valor de resistência média e o P50 15\% o menor. Aos 14 dias, P50 25\% apresenta uma tendência de crescimento que se confirma ao final do experimento, seguido pelo Testemunha, mostrando que o maior teor de finos pode diminuir os vazios e consequentemente aumentar a resistência mecânica do concreto. 0 tratamento P50 15\% apresentou a menor resistência média na idade final (Gráfico 4, em curvas).

A resistência do tratamento P50 25\% (Gráfico 4), apesar de ser muito próxima ao dos outros tratamentos, tem uma variação maior durante as idades iniciais, e superior ao Testemunha e ao P50 15\% aos 28 dias, confirmando que a substituição do agregado reciclado para concretos que alcancem resistência de $25 \mathrm{MPa}$ é favorável do ponto de vista técnico e também ambiental, já que ocorre o aproveitamento do RCD que seria descartado.

Fazendo um fechamento sobre todas as resistências médias analisadas, a maioria apresenta valores maiores que o mínimo estipulado por norma para concreto estrutural, porém, além disso, de modo geral, todos os tratamentos podem ser usados para outros processos construtivos, por exemplo, na fabricação de verga pré-moldada, elementos decorativos não estruturais, blocos pré-moldados, calçadas, pavimentos, meios-fios e argamassa de assentamento e revestimento (BRASILEIR0 e MATOS, 2015; DOMINGUES, 2013). 


\section{CONSIDERAÇ̃̃ES FINAIS}

Nas circunstâncias analisadas, e de acordo com a metodologia proposta e descrita, pode-se concluir que quando comparados ao tratamento Testemunha, 5 dos 6 tratamentos com substituição apresentaram índice de absorção superior, e que o menor índice de absorção de água foi obtido pelo tratamento P16 15\%, e, o maior índice foi observado no tratamento Composto 25\%, com absorção média respectivamente de $0,69 \%$ e 1,77\%.

Para os valores de resistência, começando pelos 3 dias de idade, o menor e maior coeficiente de variação foram os tratamentos P16 15\% (2,1\%) e Composto 25\% (21,4\%). No mesmo período a maior média de resistência obtida foi no tratamento P50 15\% e a menor no P16 25\%, apresentando 16,7MPa e 12,9MPa, respectivamente. Aos 7 dias de idade, o menor e maior coeficiente de variação foram os tratamentos P16 25\%, com 3,7\% e P16 15\% com 19,1\%. Também aos 7 dias, a maior média de resistência foi no tratamento Composto 15\%, atingindo 21,3MPa, e a menor foi 14,5MPa, apresentado no P16 15\%. Para os tratamentos analisados aos 14 dias, observou-se que P16 15\% apresentou o maior coeficiente de variação (16,0\%) e P16 25\% o menor (4,0\%). A resistência à compressão, aos 14 dias, teve média maior no tratamento P50 15\%, com valor de 23,2MPa, e menor no P16 25\% (17,2MPa). Já aos 28 dias o maior coeficiente de variação ocorreu no P16 15\% (22,6\%) e o menor no tratamento Testemunha (5,9\%). A resistência final, nesse período, mostrou-se maior no tratamento P50 25\%, com média de 27,7MPa, e menor no P16 25\%, com 19,4MPa.

Com base nos valores obtidos, é possível concluir que o uso de RCD pode ser utilizado para a produção de peças estruturais quando padronizada a sua granulometria bem como seu percentual de teor na mistura. Já é consagrado pela literatura que do ponto de vista técnico 0 uso de RCD (com apropriado teor na mistura) como forma de agregado miúdo para produção de peças de concretos não estruturais é possível e eficiente. Mesmo com resultados maiores que 25MPa (valor mínimo de resistência conforme ABNT NBR6118:2014), deve-se considerar que ainda não há normas técnicas que mencionem o uso de RCD em peças de concretos estruturais. A utilização do material mostra-se uma alternativa para solucionar problemas ambientais e econômicos da indústria da construção civil. Para fazer melhor uso dessa tecnologia, as características de agregados oriundos de RCD devem ser constantemente estudadas. 


\section{REFERÊNCIAS BIBLIOGRÁFICAS}

AMBR0ZZEWICZ, P. H. L. Materiais de construção: normas, especificações, aplicação e ensaios de laboratório. 1 ed. São Paulo: PINI, 2012.

ANGUL0, S. C; FIGUEIRED0, A. D. Concreto com agregados reciclados. IBRACON, (Ciência e Tecnologia para 0 Desenvolvimento do Concreto e da Construção Civil), São Paulo, 1 ed., v.2, p.1732-1733, 2011.

ASSOCIAÇÃO BRASILEIRA DE NORMAS TÉCNICAS (2003). ABNT NBR NM248 - agregados - determinação da composição granulométrica, Rio de Janeiro, Brasil.

Brasil.

(2007). ABNT NBR5739 concreto - ensaio de compressão de corpos-de-prova cilíndricos. Rio de Janeiro,

(2009). ABNT NBR9778-2 argamassa e concreto endurecidos - determinação da absorção de água, índice de vazios e massa específica, Rio de Janeiro, Brasil.

(2009). ABNT NBR7211 - agregado para concreto - especificação, Rio de Janeiro, Brasil.

(2012). ABNT NBR8451-1 - postes de concreto armado e protendido para redes de distribuição e de transmissão de energia elétrica - requisitos, Rio de Janeiro, Brasil.

(2014). ABNT NBR6118 projeto de estruturas de concreto - procedimento, Rio de Janeiro, Brasil.

Brasil.

(2016). ABNT NBR5738 concreto - procedimento para moldagem e cura de corpos-de-prova, Rio de Janeiro,

(2016). ABNT NBR NM IS07500-1 materiais metálicos - calibração e verificação de máquinas de ensaio estático uniaxial. Rio de Janeiro, Brasil.

BAZUCO, R. S. Utilização de agregados reciclados de concreto para produção de novos concretos. 1999. Dissertação (Mestrado em Engenharia Civil) - Universidade Federal de Santa Catarina, Florianópolis.

BRASILEIR0, L. L; MATOS, J. M. E. Revisão bibliográfica: reutilização de resíduos da construção e demolição na indústria da construção civil. Órgão Oficial da Associação Brasileira de Cerâmica, São Paulo, v.61, n.358, p.178-189, 2015.

CABRAL, A. E. B; MOREIRA, K. M. V. Resíduos da construção civil. Manual sobre os resíduos sólidos da construção civil. SINDUSCON CE, Fortaleza, Capítulo 8, 2011.

DOMINGUES, D. Contribuição ao estudo de dosagem do concreto com agregado de RCD. 2013. Monografia (Bacharel em Engenharia Civil) - Universidade da Amazônia, Belém.

FIGUEIRED0, A; COSTA, V; PEDROSA, T; SOUZA, L; SILVA, D. Considerações sobre a água como agente causador das manifestações patológicas em estruturas de concreto. SEMIPAR (Seminário de Patologia e Recuperação Estrutural), Recife, v.l, n.l, 2016.

G0MES, L. C. Estudo do sistema de lajes mistas com fôrma de aço incorporada empregando concreto estrutural leve. 2001. Dissertação (Mestrado em Engenharia Civil) - Universidade Federal de Minas Gerais, Minas Gerais.

HOPPEN, C; PORTELLA, K. F; JOUKOSKI, A; TRINDADE, E. M; ANDREÓLI, C. V. Uso de lodo de estação de tratamento de água centrifugado em matriz de concreto de cimento Portland para reduzir o impacto ambiental. Curitiba, Quim. Nova, v.29, n.l, p.82, 2006.

JOHN, V. M. Reciclagem de resíduos na construção civil: contribuição à metodologia de pesquisa e desenvolvimento. 2000. Tese (Livre Docência) - Universidade de São Paulo, São Paulo. 
KARPINSKI, L. A; PANDOLFO, A; REINEHER, R; GUIMARÃES, J. C. B; PANDOLFO, L. M; . Gestão diferenciada de resíduos da construção civil. Uma abordagem ambiental. EDIPUCRS, p.46,87, 2009. Pontifícia Universidade Católica do Rio Grande do Sul, Porto Alegre.

LEITE, M. B. Avaliação de propriedades mecânicas de concretos produzidos com agregados reciclados de resíduos de construção e demolição. 2001. Tese (Doutorado em Engenharia Civil) - Universidade Federal do Rio Grande do Sul, Porto Alegre.

MARTINS, F. G. Gestão e gerenciamento de resíduos da construção civil em obras de grande porte - estudo de caso. 2012. Dissertação (Mestrado em Ciências, Programa de Engenharia Hidráulica e Saneamento) - Universidade de São Paulo, São Carlos.

PULLEN, S; CHIVERALLS, K; ZILLANTE, G; PALMER, J; WILSON, L; ZUO, J. Minimising the impact of resource consumption in the design and construction of buildings. ANNUAL CONFERENCE OF THE ARCHITECTURAL SCIENCE ASSOCIATION, Queensland, 2012.

SANTOR0, J. F; KRIPKA, M. Determinação das emissões de dióxido de carbono das matérias primas do concreto produzido na região norte do Rio Grande do Sul. Ambiente Construído, Porto Alegre, v.16, n.2, p.35-49, 2016.

TAVARES, L. M; KAZMIERCZAK, C. S. Estudo da influência dos agregados de concreto reciclado em concretos permeáveis. IBRACON, (Revista IBRACON de estruturas e materiais), São Paulo, v.9, n.1, p.75-90, 2016.

TENÓRI0, J. L. T. Avaliação de propriedades do concreto produzido com agregados reciclados de resíduos de construção e demolição visando aplicações estruturais. 2007. Dissertação (Mestrado em Engenharia Civil) Universidade Federal de Alagoas, Maceió. 